\title{
7
}

\section{Mainstreaming Science and Human Rights in UNESCO}

\author{
Yvonne Donders and Konstantinos Tararas
}

\section{$7 \cdot 1$ INTRODUCTION}

The promotion of justice, the rule of law, and human rights as prerequisites for the consolidation of peace and security is common ground in the United Nations (UN) system. The uniqueness of the mandate of the United Nations Educational, Scientific and Cultural Organization (UNESCO) lies in the specificity of its pathway and its approach to peace. For UNESCO, the achievement of these goals is promoted through greater "collaboration among the nations through education, science and culture" (Article 1 UNESCO Constitution). In addition to delineating the Organization's playing field, this proclamation carries a double symbolic value. Firstly, it presages the inclusion of a science-related human right in the Universal Declaration of Human Rights (UDHR). Secondly, it places emphasis on the significance of international cooperation and exchange if science is to fulfil its role in promoting human well-being. While education is a field where competition among UN agencies grew considerably over the years, the broad domains of science and culture are still mainly the prerogative of UNESCO.

By virtue of this mandate, UNESCO has adopted legal instruments and has developed programmes and activities in the field of science and human rights, most notably in the field of bioethics and the ethics of science. Its Member States have created several bodies to advise on issues and challenges relating to these topics: the Intergovernmental Bioethics Committee $(\mathrm{IGBC})^{2}$ composed of representatives of Member States; the International Bioethics Committee (IBC) $)^{3}$ composed of

1 UNESCO Constitution, adopted in London on November 16, 1945, entry into force November 1946. The authors are responsible for the choice and the presentation of the facts contained in this chapter and for the opinions expressed therein, which are not necessarily those of UNESCO and do not commit the Organization.

2 The Intergovernmental Bioethics Committee (IGBC) was created in 1998, under Article 11 of the Statutes of the International Bioethics Committee (IBC). Comprised of thirty-six Member States, it examines the advice and recommendations of the IBC and recommends follow-up action. More information is available at: https://en.unesco.org/themes/ethics-science-and-technology/igbc.

3 The International Bioethics Committee (IBC) is a body of thirty-six independent experts that since its creation in 1993 follows progress in the life sciences and its applications in order to ensure respect for 
independent experts; and the World Commission on the Ethics of Scientific Knowledge and Technology (COMEST), ${ }^{4}$ also composed of independent experts.

The articulation of human rights and science is interwoven with UNESCO's efforts to implement new global frameworks such as the 2030 Agenda for Sustainable Development and its Sustainable Development Goals (SDGs) and the New Urban Agenda. It was also an important dimension of the Organization's responses to the challenges of the COVID-19 pandemic. This approach builds on UNESCO's lead role in the Scientific Advisory Board, the UN expert body that was established in 2013 to bring science to the core of the sustainable development agenda.

This contribution discusses how UNESCO has worked on human rights in relation to science, and on science in relation to human rights with emphasis on standard-setting. It attempts to foreground the core approaches underpinning these efforts; to highlight the evolution in the Organization's thinking; and to show to what extent these are aligned with and promote the advancement of the right to enjoy the benefits of scientific progress as included in human rights instruments, in particular the dimensions of scientific freedom, protection against harm, benefit sharing, and international cooperation.

\subsection{FOUNDATIONS OF UNESCO'S ACTION ON HUMAN RIGHTS}

\subsubsection{Mandate}

The vision of an inextricable link between peace and the realization of human rights is the foundation of UNESCO's mandate and its work in this domain. The Organization's constitutional commitment was immediately translated into action. UNESCO contributed to the reflection underpinning the elaboration of the UDHR. Through a committee especially created in 1947, UNESCO studied the philosophical foundations of human rights in order to foreground convergences between various cultures and schools of thought. ${ }^{5}$ UNESCO was also the first UN entity that undertook to disseminate information about the UDHR through mass communication programs and teaching materials in schools, and to incorporate it in its programs. ${ }^{6}$ In the following decades, drawing on its normative action, UNESCO contributed to the promotion of human rights in its fields of competence through research, capacity development, advocacy, and agenda-setting.

human dignity and freedom. More information is available at: https://en.unesco.org/themes/ethicsscience-and-technology/ibc.

4 The World Commission on the Ethics of Scientific Knowledge and Technology COMEST is an eighteen-member advisory body and forum of reflection that was set up by UNESCO in 1998. More information is available at: https://en.unesco.org/themes/ethics-science-and-technology/comest.

5 UNESCO, Report of the Meeting of the UNESCO Committee on the Philosophical Principles on the Rights of Man (1947); available at: http://unesdoc.unesco.org/images/oo12/o01243/124347Eb.pdf.

6 Records of the General Conference of UNESCO, third session, Beirut, 1948, Volume II Resolutions (Miscellaneous Resolutions, 8 UDHR, page 118); available at: http://unesdoc.unesco.org/images/oon1/ oo1145/114593e.pdf. 
While UNESCO's constitutional mandate is broad and covers the promotion of all human rights, its action focuses on the rights directly linked to its mandate. These include: the right to education; the right to freedom of opinion and expression, including the right to seek, receive, and impart information; the right to take part in cultural life and artistic freedom; the right to water and sanitation; and the right to enjoy the benefits of scientific progress and its applications.

UNESCO's general commitment to human rights mainstreaming was reaffirmed in the early zooos. The Organization's 2003 Human Rights Strategy elevated the integration of a human rights-based approach (HRBA) in all its activities to a housewide priority. This UN-wide approach, forged out of the momentum of the $1997 \mathrm{UN}$ Reform, implies that the work of UN Agencies and Programmes, including that of UNESCO, is guided by human rights principles, as laid down in the UDHR and other international human rights instruments. These principles include: universality; indivisibility and interdependence of all human rights; equality and nondiscrimination; participation and inclusion; accountability; and the rule of law. ${ }^{7} \mathrm{HRBA}$ is a key programming principle in UNESCO's Medium-Term Strategy for 2014-2021, reaffirmed in the draft Medium-Term Strategy for 2022-2029 ${ }^{8}$, and a cornerstone for the implementation of gender equality, one of the Organization's two global priorities. ${ }^{9}$

The right to enjoy the benefits of scientific progress and its applications is included in Article 27 UDHR and in Article 15(1)(b) of the International Covenant on Economic, Social and Cultural Rights (ICESCR). These instruments recognize that this right includes the right of individuals to enjoy the benefits of scientific advancement and the rights of scientists to freely conduct science and to have the results of their work protected. Another inherent component of the right to enjoy the benefits of scientific progress and its applications is the protection from possible harmful effects of science. A cross-cutting dimension of this right, and of the Covenant, is international cooperation.

UNESCO has actively supported the elaboration of this right. Most importantly, it drew the right from its oblivion by initiating a series of experts' meetings that led to the adoption by a group of experts of the Venice Statement on the Right to Enjoy the Benefits of Scientific Progress and its

7 According to the UN Statement of Common Understanding on Human Rights-Based Approache to Development Cooperation and Programming, adopted in 2003, the HRBA entails that: all programs of development cooperation, policies and technical assistance should further the realization of human rights; human rights standards and principles derived guide all development cooperation and programming in all sectors and in all phases of the programming process, and development cooperation contributes to the development of the capacities of "duty-bearers" to meet their obligations and/or of "rights-holders" to claim their rights.

8 Medium-Term Strategy for 2014-2021, approved by the General Conference at its 37th session (General Conference resolution $37 \mathrm{C} /$ Res.1), Document $37 \mathrm{C} / 4$, paragraph 23; Executive Board, Draft Medium Term Strategy for 2022-2029 (41C/4), 10 March 2021, Document 211 EX/18.I.

9 See the UNESCO Gender Equality Action Plan, available at: https://unesdoc.unesco.org/ark:/48223/ pfooo0227222/PDF/227222eng.pdf.multi. 
Applications in July 2009. ${ }^{10}$ This statement aimed to clarify the normative content of the right, as well as to generate discussion among all relevant stakeholders with a view to enhancing its implementation.

\subsubsection{UN Global Frameworks}

Being part of the UN family, UNESCO's work fits within a broader context defined by human rights-driven global action frameworks, most notably the 2030 Agenda for Sustainable Development and the SDGs, and the New Urban Agenda. Agenda 2030 and the SDGs embody an unprecedented universal consensus on key prerequisites for sustainable human development that are anchored in human rights. Guided by the commitment of "leaving no one behind," Agenda 2030 marks a paradigm shift towards an inclusive and transformative vision of human development that establishes clear imperatives for the UN system regarding respect for, protection of, and fulfilment of human rights. Moreover, acknowledging their close interconnection, Agenda 2030 endorses a holistic approach to the set of challenges at hand, significantly expanding the list prioritized by the Millennium Development Goals (MDGs) and making the elimination of inequalities a transversal thread. Contrary to previous political commitments, Agenda 2030 constitutes - to paraphrase the preamble of the UDHR - "a common standard of achievement for all peoples and all nations" towards which all efforts must converge. Interestingly, science is a crosscutting thread of Agenda 2030. The preamble's acknowledgement of science, technology and innovation (STI) as a key driver for sustainable development, is mirrored by the inclusion of as many as twenty-three STI-related SDG targets.

The New Urban Agenda ${ }^{11}$ localizes the commitments of Agenda 2030 and the content of the SDGs by acknowledging that local authorities are also responsible for protecting, respecting, and fulfilling the human rights of the inhabitants at the city level, in line with central governments.

UNESCO has placed the implementation of Agenda 2030 at the core of its action. The Organization focuses on and contributes significantly to nine SDGs, namely: SDG 4 (Quality Education); SGD 5 (Gender Equality); SDG 6 (Clean Water and Sanitation); SDG 9 (Industry, Innovation and Infrastructure); SDG 11 (Sustainable Cities and Communities); SDG 13 (Climate Action); SDG 14 (Life below Water); SDG 15 (Life on Land), and SDG 16 (Peace, Justice and Strong Institutions). ${ }^{12}$ In

10 Venice Statement on the Right to Enjoy the Benefits of Scientific Progress, adopted July 17, 2009, available at https://unesdoc.unesco.org/ark:/48223/pfoooo185558. This statement was one of the inspirational sources of General Comment No. 25 (2020) on science and economic, social and cultural rights Art. 15.1.b, 15.2, 15.3 and 15.4, adopted by the Committee on Economic, Social and Cultural Rights in April 2020.

11 The New Urban Agenda was adopted by all UN Member States in October 2016 at the United Nations Conference on Housing and Sustainable Urban Development (Habitat III) in Quito, Ecuador; available at: http://habitat3.org/wp-content/uploads/NUA-English.pdf.

12 An overview of how UNESCO moves forward the Agenda 2030 is available at: https://unesdoc .unesco.org/ark:/48223/pfooo0247785. 
TABLE 7.1 Science Technology and Innovation (STI) and Agenda 2030

\begin{tabular}{|c|c|c|}
\hline $\begin{array}{l}\text { Areas explicitly mentioned } \\
\text { in Agenda } 2030\end{array}$ & $\begin{array}{l}\text { SDGs making explicit } \\
\text { references to STI }\end{array}$ & $\begin{array}{l}\text { SDG targets making specific } \\
\text { references to STI }\end{array}$ \\
\hline Science & $4 ; 14$ & 4.b $; 14.3 ; 14.4 ; 14.5$ \\
\hline Technology & $1 ; 2 ; 5 ; 6 ; 7 ; 9 ; 17$ & $\begin{array}{l}\text { 1.4; } 2 . a ; 5 . b ; 6 . a ; 7 . a ; 7 . b ; 9.4 ; 9 . a ; \\
\quad \text { 9.c; } 17.7 ; 17.16\end{array}$ \\
\hline Innovation & 8 & $8.2 ; 8.3$ \\
\hline STI & $9 ; 12 ; 14 ; 17$ & $9.5 ; 9 . b ; 12 . a ; 14 . a ; 17.6 ; 17.8$ \\
\hline
\end{tabular}

connection with these SDGs, UNESCO has the following key roles: internationally recognized global or shared leadership and coordination; monitoring and benchmarking; global advocacy to sustain political commitment; leading or co-leading global multi-stakeholder coalitions; normative mandate and provider of upstream policy support and capacity development. Furthermore, the Organization contributes to SDG 1 and 10, and is concerned with aspects of SDG $17 .{ }^{13}$

\section{$7 \cdot 3$ UNESCO'S APPROACH TO SCIENCE AND HUMAN RIGHTS}

UNESCO's work in the field of science and human rights, and in particular the right to enjoy the benefits of scientific progress and its applications, has evolved significantly. The Organization has explicitly focused on promoting an ethical and rights-based approach to the advancement of science and technology, inter alia, by fostering the rights and freedoms of scientific researchers and an equitable sharing of the benefits of that research. It has also addressed the ethical challenges deriving from cutting-edge science, for instance in connection with bioengineering and biotechnology, and, more recently artificial intelligence, big data, and the Internet of Things. Its work has also supported a stronger interlinkage between scientific evidence and policy-making and it has fostered gender equality in sciences by strengthening the opportunities of women. A good example of the last is UNESCO's program For Women in Science, which it has hosted since 1998 in cooperation with L'Oréal. The motto of this program is "the world needs science, science needs women." It aims to reward excellent female scientists for their important contributions to the progress of science, either in life sciences or in the fields of physical sciences, mathematics, and computer science. In the last 20 years, more than 3100 scientists from 117 countries have been supported and more than 50 countries grant national and regional scholarships under the flag of this program. ${ }^{14}$

13 Ibid

14 More information on this programme can be found at: www.forwomeninscience.com/en/home. 


\subsubsection{Early Approaches: Do No Harm, Benefits Sharing, and International Cooperation}

In the decades after the adoption of the ICESCR, States focused on three aspects of science. The first aspect was promoting "the optimum utilization of science and scientific methods for the benefit of mankind and for the preservation of peace and the reduction of international tensions." ${ }^{15}$ The second was to address "dangers which constitute a threat, especially in cases where the results of scientific research are used against mankind's vital interests in order to prepare wars involving destruction on a massive scale or for purposes of the exploitation of one nation by another, and in any event give rise to complex ethical and legal problems. ${ }^{{ }^{16}}$ Finally, States aimed to promote international cooperation so that the full potential of scientific and technological knowledge could be promptly geared to the benefit of all peoples. ${ }^{17}$

These dimensions were explicitly included in the Recommendation on the Status of Scientific Researchers, adopted by the Member States of UNESCO in 1974. The Recommendation calls upon States to foster an environment where scientific researchers can "contribute positively and constructively to the fabric of science, culture and education in their own country, as well as to the achievement of national goals, the enhancement of their fellow citizens' well-being, and the furtherance of the international ideals and objectives of the United Nations."18 At the same time, the Recommendation allows States a considerable margin of appreciation. Deviations from the Recommendation are acceptable under the condition that the cases where these apply are specified "as explicitly and narrowly as possible."19

This three-pronged approach of States is also included the Recommendation concerning Education for International Understanding, Co-operation and Peace and Education relating to Human Rights and Fundamental Freedoms adopted at the same time. Specifically, the Recommendation recognizes as an integral part of human rights education the duty to promote "the inadmissibility of using science and technology for warlike purposes and their use for the purposes of peace and progress." ${ }^{\circ}$ The Recommendation also underscores the role of education in harnessing the power of knowledge towards problem-solving and the critical role of international cooperation in this regard. ${ }^{21}$

15 Preamble of the Recommendation on the Status of Scientific Researchers, UNESCO Gen. Conf. Res. 18 C/Res.40, 18th Sess. (1974).

16 Ibid

17 Ibid, Article 19.

18 Recommendation on the Status of Scientific Researchers, UNESCO Gen. Conf. Res. 18 C/Res.4O, 18th Sess. (1974), Article 14(d).

19 Ibid., Article 14 (d).

20 Recommendation concerning Education for International Understanding, Co-operation and Peace and Education relating to Human Rights and Fundamental Freedoms, UNESCO Gen. Conf. Res. 18 C/Res. 38, 18th Sess. (1974), Article 18 (b).

21 Ibid, Articles 18, 19, and 26. 
Another general feature of UNESCO's approach is the importance allocated to culture. In a reply to a survey by the UN Commission on Human Rights in 1976, the Organization's Director-General observed that science and technology "are merely the instruments for carving out decisions made elsewhere - what we find at the fountainhead of the long and complex chain of those decisions but the determining factor of culture?" Hence, "the use made of science and technology, like pure science itself, is a matter of culture." ${ }^{\prime 22}$ The role of culture is underscored later on in the context of reflection about ethical considerations in relation to scientific discoveries and the progress of technology. A valuable dialogue between cultures is seen as crucial for bioethics, in the same way as the breaking down of barriers between disciplines. ${ }^{23}$

The approach and emphasis of the two Recommendations of 1974 actually underpin the several instruments related to science adopted around the same time in the broader context of the UN. Most of these concentrate on international cooperation in the field of science and on the possible harmful effects of science and technology with a focus on the duties of States and scientists to promote, conduct, and use science in a responsible way. For example, the Charter of Economic Rights and Duties of States, adopted by the UN General Assembly in 1974, recognizes a right of States - not of individuals - to benefit from scientific advancement and developments in science and technology. It also calls upon States to promote international scientific and technological cooperation and the transfer of technology to developing countries, as well as facilitate access of developing countries to the achievements of modern science and technology (Article 13).

Similarly, the Declaration on the Use of Scientific and Technological Progress in the Interests of Peace and for the Benefit of Mankind, adopted by the UN General Assembly in 1975, concentrates on the possible abusive use of science contrary to human rights. Its preamble acknowledges that scientific and technological achievements could improve the conditions of peoples and nations and, at the same time, cause social problems or threaten human rights and fundamental freedoms. Other issues in this Declaration include non-discrimination and international cooperation to ensure that the results of science and technology are used in the interests of peace and security, and for the economic and social development of peoples. It is further laid down that States should prevent the use of scientific and technological development to limit the enjoyment of human rights and protect the population from possible harmful effects of the misuse of science and technology (Article 2).

22 Report of the Secretary-General, Human Rights and Scientific and Technological Developments, The balance which should be established between scientific and technological progress and the intellectual, spiritual, cultural and moral advancement of humanity, Commission on Human Rights, 32nd session, Document E/CN.4/1199/Add.1 of February 2, 1976, para. 196, available at: https:// digitallibrary.un.org/record/720321? ln=en.

23 Report by the Director-General on the possibility of drawing up an international instrument on the protection of the human genome, Document 28 C/38 of September 7, 1995, para. 7. 


\subsubsection{Emphasis on Science and (Bio-)Ethics}

About two decades later, UNESCO initiated the adoption of several international instruments relating to science in relation to ethics and bioethics. The Universal Declaration on the Human Genome and Human Rights, adopted by UNESCO's General Conference in 1997 and endorsed by the UN General Assembly in 1998, focuses on the potential abuse of science and research. In this sense, it echoes a series of General Conference resolutions that express concern and call upon UNESCO to take initiatives around such abuse of science, such as the development of sophisticated weaponry. ${ }^{24}$ The Declaration states, for instance, that researchers have special responsibilities in carrying out their research, including meticulousness, caution, intellectual honesty, and integrity (Article 13). It also states that persons have the right to be informed about research on their genome and that such research should in principle not be carried out without a person's consent. If such consent is not possible, research should be carried out only for the person's health benefit or the health benefit of others (Article 5). The Declaration also urges States to promote international dissemination of knowledge, in particular between industrialized and developing countries (Article 18).

The idea of sharing the benefits of science is more clearly present in the International Declaration on Human Genetic Data, adopted by the General Conference of UNESCO in 2003. According to this Declaration, the benefits of science, including access to medical care, the provision of new diagnostics, facilities for new treatments or drugs deriving from research, and support for health services, should be shared with society as a whole and with the international community (Article 19).

An explicit reference to the sharing of benefits of science can be found in the Universal Declaration on Bioethics and Human Rights, adopted by UNESCO's General Conference in 2005. Article 15 includes that "[b]enefits resulting from any scientific research and its applications should be shared with society as a whole and within the international community, in particular with developing countries." Part of such benefits could be access to scientific and technological knowledge (Article 15(1)e). This provision focuses more on the sharing of the results of science and less on the advancement of science or the freedom to conduct science. UNESCO's International Bioethics Committee (IBC) extensively elaborated on the concept of benefit sharing in a report issued in $2015 .{ }^{25}$ It explicitly linked

24 UNESCO's General Conference 29 C/Resolution 16, adopting the Declaration, recalled a series of resolutions of the 198 os and early 1990 (namely $22 \mathrm{C} /$ Resolution 13.1, $23 \mathrm{C} /$ Resolution 13.1, $24 \mathrm{C} /$ Resolution 13.1, 25 C/Resolutions 5.2and 7.3, 27 C/Resolution 5.15 and 28 C/Resolutions 0.12, 2.1 and 2.2 ) that urged "UNESCO to promote and develop ethical studies, and the actions arising out of them, on the consequences of scientific and technological progress in the fields of biology and genetics, within the framework of respect for human rights and fundamental freedoms."

25 International Bioethics Committee, Draft Report of the IBC on the principle of the sharing of benefits, UNESCO Doc. SHS/YES/IBC-22/15/3 REV.2, available at https://unesdoc.unesco.org/ark:/ $48223 /$ pfoooo233230. 
Article 15 of the Declaration to Article 27 UDHR and Article 15 ICESCR. It reaffirmed the importance of sharing the benefits of science with society as a whole, and with the international community, while also addressing the possible tradeoff with the protection of intellectual property and patents. The IBC further maintained that sharing should be seen as participation and not as top-down beneficence, emphasizing the importance of capacity building and science education, open access to information, and empowerment and participation in the production of knowledge.

\subsubsection{Broadening the Scope: Science-Based Decision Making}

\subsubsection{UNESCO Declaration of Ethical Principles in Relation to Climate Change}

In recent years, UNESCO's work in the field of science and human rights was given a new impetus. Much influenced by the global discussions on sustainable development and climate change, Member States of UNESCO elaborated and adopted in 2017 the UNESCO Declaration of Ethical Principles in relation to Climate Change. This Declaration emphasizes the fundamental importance of science, technological innovation, relevant knowledge, and education for sustainable development in the response to climate change. Several of the human rights dimensions of science, such as prevention of harm and international cooperation, are reflected in the Declaration. The Declaration adds an important new dimension in relation to science and human rights, namely the promotion of decision-making based on science.

As regards the prevention of harm, the Declaration maintains in Article 2 that people should aim to "anticipate, avoid or minimize harm, wherever it might emerge, from climate change, as well as from climate mitigation and adaptation policies and actions." Science is also relevant in relation to another dimension of possible harm, namely the precautionary principle. Article 3 states that: "Where there are threats of serious or irreversible harm, a lack of full scientific certainty should not be used as a reason for postponing cost-effective measures to anticipate, prevent or minimize the causes of climate change and mitigate its adverse effects."

International cooperation is included in several parts of the Declaration. For instance, Article 2 states that States should "seek and promote transnational cooperation before deploying new technologies that may have negative transnational impacts." Article 7 includes that "scientific cooperation and capacity building should be strengthened in developing countries."

Scientific freedom is less present in the Declaration, but it is included in Article 7(4) that States should "take measures which help protect and maintain the independence of science and the integrity of the scientific process." 
The Declaration adds explicit provisions on scientific knowledge and integrity in decision-making. Article $7(1)$ states that "decisions should be based on, and guided by, the best available knowledge from the natural and social sciences, including interdisciplinary and transdisciplinary science, and by taking into account, as appropriate, local, traditional and indigenous knowledge." States should therefore "build effective mechanisms to strengthen the interface between science and policy to ensure a strong knowledge base in decision-making" (Article $7(4) \mathrm{d})$.

\subsubsection{UNESCO Recommendation on Science and Scientific Researchers}

One of the most crucial instruments by UNESCO that connects science and human rights is the Revised Recommendation on Science and Scientific Researchers, also adopted in 2017. This document supersedes the Recommendation on the Status of Scientific Researchers of 1974. As the Director-General noted in her report on the revision, the Recommendation reflects a "conceptual paradigm shift toward systematically addressing risks and responsibilities in science, while recognizing that the freedom of expression and conscience of researchers and their professionalism is its backbone." ${ }^{26}$ The idea driving the Recommendation was the establishment of closer links with the SDGs, and in particular Target 9.5 that aims to enhance scientific research. The Recommendation underscores the importance of another application of science, namely the use of scientific and technological knowledge in decisionmaking (paragraphs $5(\mathrm{~g}), 7,8$, and 9).

The revised Recommendation sets out the operational standards for a contemporary and forward-looking vision for science. A main innovation of the Recommendation is the recognition that harnessing the transformative power of science requires a holistic approach, which is anchored unequivocally in human rights.

The Recommendation adopts a broad strategy, looking at the whole process of science as a departure point for determining the role of scientific researchers. In doing so, the Recommendation pays specific attention to new developments, such as the internationalization of science and mobility of scientists, the changing security and environmental concerns, the increased role of the private sector, the increased concern about the ethical aspects of the science enterprise, and the interdisciplinary nature of science, including social and human sciences. All these have led to an increased recognition that the responsibilities of scientists have widened and that a firm link with human rights is required.

Human rights is set as a cornerstone for building a sound science, technology, and innovation system indispensable for achieving sustainable development. In that spirit, the Recommendation incorporates human rights in multiple ways. By

26 UNESCO Doc. SHS/BIO/SSR/2017/1, Revision of the Recommendation on the Status of Scientific Researchers (1974), May 17, 2017, p. 3, para. 8. 
explicitly setting the human right to share in scientific advancement and its benefits (paragraph 21) as a reference point, the Recommendation broadly endorses its different elements, including the sharing of its benefits, academic freedom, protection from possible harm, and international cooperation. It also refers to the human rights of scientists, the rights of people to access knowledge produced by science, and the rights of people affected.

Among its many important principles, three deserve to be highlighted in this context. First of all, emphasis is placed on the responsibility of science towards UN ideals of human dignity, progress, justice, peace, welfare of humankind, and respect for the environment (paragraph 4) and the need to subject scientific conduct to universal human rights standards (paragraphs 18a,e, 20a,b,c, 21, 22, 42). As a result, science should be fully integrated into efforts to develop more humane, just, and inclusive societies. A second feature relates to the need for science to interact meaningfully with society and vice versa towards tackling global challenges (paragraphs $4,5 \mathrm{c}, 13 \mathrm{~d}, 19,20,22)$. This calls for the active participation of society in science and research in a democratic and horizontal manner, through the identification of knowledge needs, the conduct of scientific research, and the use of results. Finally, the Recommendation promotes science as a common good (paragraphs 6, $\left.13 \mathrm{e}, 16 \mathrm{a}-\mathrm{v}, 18 \mathrm{~b}, \mathrm{c}, \mathrm{d}, 21,34 \mathrm{e}, 35,36,3^{8}\right)$. According to the text, this entails that public funding of research and development should be perceived as a form of public investment, the returns on which are long-term and serve the public interest. Likewise, States should facilitate and encourage open science, including the sharing of data, methods, results, and the knowledge derived from it, in view of its potential benefits. It also entails the removal of obstacles preventing women and other underrepresented groups from receiving, on an equal footing, basic education, training and, ultimately, access to employment in scientific fields. ${ }^{27}$

\subsubsection{UNESCO and the UN Scientific Advisory Board (2013-2016)}

The work of UNESCO in the UN Scientific Board is also worth brief exploration. The need to bring science to the core of the sustainable development agenda was acknowledged by the UN Secretary-General's High-level Panel on Global Sustainability in its report entitled "Resilient People, Resilient Planet: A Future Worth Choosing," adopted in January 2012. ${ }^{28}$ Beyond addressing global challenges, the Panel insisted on the importance of a strengthened science policy interface as a necessary complement to efforts on economic and social aspects, and factors such as inequalities. The Panel considered that this objective could be best achieved either by "naming a chief scientific adviser or establishing a scientific advisory board with diverse knowledge and experience" (Recommendation 51, page 75).

\footnotetext{
27 The annex to UNESCO's General Conference 39 C/Resolution 85 that adopted the Recommendation identifies a set of ten key related areas.

28 The Report is available at: https://en.unesco.org/system/files/GSP_Report_web_final.pdf.
} 
UNESCO played a decisive role in taking this Recommendation forward. It convened the Executive Heads of UN organizations with a science-related mandate and representatives of major scientific bodies into an ad hoc group mandated to provide advice to the SG and the UN system as a whole. Recognizing the strategic opportunity, the ad hoc group opted for the establishment of a representative body, the Scientific Advisory Board. This body came into being in September 2013. UNESCO hosted its secretariat and the UNESCO DG took the lead in establishing the body and taking up the function of its chair. ${ }^{29}$

The Scientific Advisory Board was given an ambitious mandate. Its areas of focus included improving coordination among UN entities having a mandate in science, technology, engineering, and humanities; avoiding mission creep and overlap and curbing counter-productive competition; advising on 2030 Agenda science priorities; and providing insights on the promotion of democratic global governance for a responsible and ethical development of science that reinforces sustainability. ${ }^{30}$

To fulfil its mandate, the Board was tasked to connect and mobilize all relevant scientific fields for the purpose of fostering coherence. And so it covered the basic sciences, engineering and technology, social science and humanities, ethics, health, economic, behavioral, environmental, and agricultural sciences.

Thus defined, the mandate given to the Scientific Advisory Board opened important avenues for connecting science with human rights considerations. The final report of the Scientific Advisory Board with its main findings and recommendations, submitted in September 2016, reveals that human rights-related considerations were on its radar. First of all, it explicitly recognized science as a public good, which deserves to be valued more highly, employed more widely, and used effectively by decision-makers at all levels. ${ }^{31}$

A corollary to considering science a public good was the emphasis on a societypolicy-science interface. The science process should thus involve a diversity of stakeholders, including government, civil society, indigenous peoples and local communities, businesses, academia, and research organizations, each with their own accountabilities. This way, the Board considered, the diverse perspectives and priorities could be synthesized in a manner aligned with the evidence and serve the long-term interests of society and the planet. ${ }^{32}$

Another important aspect related to human rights is the advocacy for a holistic approach to science with emphasis placed both on knowledge production for innovation (basic research) and applied research, as well as on linking such factors as health, education, opportunity, incomes, social mobility, and nutrition. This

29 More information available at: https://en.unesco.org/themes/science-sustainable-future/scientificadvisory-board-united-nations-secretary-general.

30 Ibid

${ }^{31}$ The Future of Scientific Advice for the United Nations - a Summary Report to the Secretary-General of the United Nations from the Scientific Advisory Board, September 2016, available at https:// unesdoc.unesco.org/ark:/48223/pfooo $245801 / \mathrm{PDF} / 245801$ ng.pdf.multi.

32 Ibid, p. 17-21. 
reaffirmed the close interlinkages between the right to enjoy the benefits of scientific progress and other human rights related to health, food, labor, and education.

Finally, the influence of human rights and the "leave no one behind" vision of Agenda 2030 is evident in its emphasis on inequalities. The report calls for codesigning and co-ownership by all as the basis for developing science, technology and innovation across the board. It stresses that the complexity of today's world and its challenges require the mobilization of resources and assets in all parts of the world, developing and developed, as it passes imperatively through the elimination of gender disparities. ${ }^{33}$

A full assessment of the work of the Scientific Advisory Board is outside the scope of this contribution. However, it is fair to say that the Board partially met the expectations surrounding its creation. Counted among its strengths and positive contributions are its call for a more central role for science in fostering sustainable development and also the emphasis on a holistic approach to science. Another is its echoing of fundamental principles of Agenda 2030, in particular transparency, participation, and inclusion, and the elimination of inequalities. It is probably no coincidence that these elements were key to the vision for science embodied in the 2017 Recommendation on Science and Scientific Researchers. Yet, the Board did not succeed in building the case for a holistic approach to human rights with the right to enjoy the benefits of scientific progress and its applications at its core, at least not using explicit terms. That was a missed opportunity. A strong recommendation towards such an orientation at the beginning of the SDG era could perhaps have helped integrate a human rights lens into the monitoring process of specific targets and indicators.

\section{$7 \cdot 4$ CONCLUDING REMARKS}

The significant role of science in consolidating peace, fostering human well-being, and achieving sustainability cannot be overestimated. Hence, it is only natural that science, technology, and innovation were woven into the fabric of the 2030 Agenda for Sustainable Development, cutting across virtually all of the seventeen SDGs, including their targets and means of implementation.

This contribution shows that UNESCO, with its specific mandate in the field of science, has worked on human rights in relation to science, and on science in relation to human rights, in many different ways. Shifting over the years from a narrower to a more holistic approach, it has developed numerous instruments that connect the advancement of science to ethical and human rights standards and principles. These include academic freedom and protection of the rights of scientists, protection against harm, sharing benefits of scientific and technological advancements, including related knowledge and their applications, international cooperation and, more recently, science-based decision-making. In addition,

33 Ibid, p. 22-24. 
UNESCO embarked since November 2019 on the elaboration of two new instruments: on ethics of artificial intelligence ${ }^{34}$ and on open science, ${ }^{35}$ potentially enhancing the science-related normative arsenal. Standard-setting efforts have been reinforced by converging advocacy initiatives such as the Joint Appeal for Open Science, launched by the leadership of UNESCO, WHO and OHCHR in October 2020. The appeal acknowledged the right to enjoy the benefits of scientific progress and its applications as the cornerstone of efforts to promote open, inclusive and collaborative science. The idea of linking science to human rights has clearly underpinned UNESCO's position and advice during the COVID-19 pandemic. For example, it is a central tenet of the statements issued by the Organizations' ethics bodies, COMEST and IBC on global ethical considerations and on global vaccines equity and solidarity. ${ }^{36}$

It should be noted that all UNESCO science-related instruments - being declarations or recommendations and not treaties - are not legally binding upon States. Moreover, their monitoring is mostly State-driven ${ }^{37}$ and therefore not comparable to that relating to UN human rights treaties and their expert bodies.

Yet, these instruments demonstrate a large degree of consensus among States on the need to promote science as a public good accessible to all and to integrate human rights norms and principles into the advancement and promotion of science and technology and related policies. At the same time, it is important that the articulation of the link between science and human rights goes beyond the realm of aspirations.

The General Comment on science and economic, social and cultural rights, ${ }^{38}$ adopted by the Committee on Economic, Social and Cultural Rights, is a milestone in removing some of the normative ambiguity. The General Comment reserves an important place for the work of UNESCO. Further to reiterating the definition of science developed by UNESCO, the General Comment recognizes particularly the Universal Declaration on Bioethics and Human Rights and the Recommendation on Science and Scientific Researchers, as sources of inspiration for the elaboration of the relationship between science and human rights. The various dimensions of

34 More information about this process is available at: https://en.unesco.org/artificial-intelligence lethics.

35 More information about this process is available at: https://en.unesco.org/science-sustainable-future /open-science/recommendation.

$3^{6}$ Statement on COVID-19: ethical considerations from a global perspective, Document SHS/IBCCOMEST/COVID-19 REV, April 6, 2020; UNESCO's ethics commissions call for global vaccines equity and solidarity, Document SHS/BIO/IBC-COMEST/COVID-19 Vaccines, February 24, 2021.

37 According to Article 18 of the Rules of Procedure concerning recommendations to Member States and international conventions covered by the terms of Article IV, paragraph 4, of the Constitution (adopted by the General Conference at its 5 th session, and amended at its 7 th, 17th, 25th, and $32 n d$ sessions), "The General Conference shall entrust the examination of the reports on such conventions and recommendations received from Member States to the Executive Board."

$3^{8}$ Committee on Economic, Social and Cultural Rights, General Comment No. 25 (2020) on Science and economic, social and cultural rights Art. 15.1.b, 15.2, 15.3, and 15.4, April 7, 2020, UN Doc. E/C.12/ GC/25. 
academic freedom, ${ }^{39}$ protection against harm, ${ }^{40}$ sharing benefits of scientific and technological advancements, ${ }^{41}$ international cooperation, ${ }^{42}$ and science-based decision-making ${ }^{43}$ - that the Committee considers part of the core obligations of States in the implementation of the right to enjoy the benefits of scientific progress ${ }^{44}$ - are prominent in those UNESCO instruments.

In light of this development, the emphasis now needs to be placed on developing appropriate tools, instruments, and guidance for States and other stakeholders to implement these ambitious standards through sustainable laws, policies, and practices. A large part of the challenge ahead derives from the breadth of the approach. Indeed, a comprehensive vision of science - going beyond benefits sharing, and the prevention of the negative effects of scientific development - emerges as the necessary point of departure for all related efforts. The UNESCO instruments actually build that case convincingly. However, while a comprehensive approach can respond more adequately to the complexity of the issues at stake, it also raises the difficulty of translating the vision into praxis. In the absence of clear guidance and extensive State practice, the numerous and broad principles contained in the 2017 Recommendation could hamper or discourage implementation and risk transforming the instrument into an empty shell. The first monitoring of the 2017 Recommendation, launched in 2020, offers an opportunity for addressing some of the many operational challenges. However, unless that process engenders the development of specific programs by UNESCO, its Member States, and other stakeholders, the hurdles will remain high if not insurmountable.

Clearly, a positive change also depends on the uptake of issues linked to the right to enjoy the benefits of scientific progress and its applications by the Committee in its examination of periodic reports. Current reporting and the related discussions with States Parties are insufficient. The recently adopted General Comment could be an excellent tool to promote such reporting and discussions before the CESCR. An ideal development would be that monitoring by the Committee and that of the UNESCO instruments evolve to be seen as mutually beneficial and reinforcing one another. The enhanced operational convergence resulting from such an approach is likely to spill over into other human rights monitoring processes, including the Universal Periodic Review of the UN Human Rights Council where broader science-related issues remain absent.

Investing further in strengthening coordination and coherence across the UN system towards a closer articulation between science and human rights should be a priority in the years to come. Integrated approaches are necessary in view of the

43 Ibid, paras. 54 and 75 .

44 Ibid, para. 54. 
multitude of entities working in the vast realm of science. They become even more compelling given the interconnectedness between the different scientific fields at a time when the UN is expected to focus increasingly on accelerating the implementation of Agenda 2030 while coping with the consequences of the COVID-19 pandemic. The September 2019 SDG Summit addressed an urgent call for accelerated action, premised on human rights and the "leave no one behind" vision. It also reiterated the importance of science, technology and innovation for sustainable development, placing emphasis inter alia on promoting the use of scientific evidence from all fields, empowering all persons with relevant knowledge and skills and fostering international cooperation. ${ }^{45}$ Furthermore, the UN General Assembly acknowledged the need for science-based comprehensive and coordinated responses to the COVID-19 pandemic. ${ }^{6}$

Given the frenetic pace of scientific innovation but also its critical role in addressing challenges to human well-being - the COVID-19 pandemic being a tragic reminder thereof - it is crucial that the discussion about operationalizing the link between science and human rights advances urgently and that it involves all concerned stakeholders. Their ownership of contemplated solutions will be a key success factor. The increasing focus of scientific and engineering communities on problem-solving in relation to development challenges presages that a call for cooperation will not remain unanswered.

45 Gearing up for a decade of action and delivery for sustainable development: political declaration of the Sustainable Development Goals Summit (24-25 September 2019), as endorsed by the UN General Assembly by virtue of Resolution 74/4 of October 15, 2019, para. 27 (g).

$4^{6}$ General Assembly Resolution A/RES/74/306, Comprehensive and coordinated response to the coronavirus disease (COVID-19) pandemic, September 15, 2020. 